\title{
ESTUDIOS
}

\section{Sobre la relación entre ambas Américas}

Gentilmente se reclama de mí una opinión sobre qué clase de contactos fecundos pudieran establecerse entre las porciones máximas de este continente, última sede para la esperanza y la paz. Tratar metódicamente la cuestión requeriría ante todo exponer con claridad los rasgos esenciales de las Américas del Sur y del Norte, asunto por demás intrincado. Por otra parte, ¿ cómo hablar de nada de esto sin caer en lugares comunes muy batidos, y al mismo tiempo sin lastimar la despierta susceptibilidad de tantos países? Y más peligroso todavía considero la ininteligencia de algunos para interpretar lo que se dice, y distinguir entre lo que es analizar y lo que sería zaherir. Las vanidades nacionales son postes de alta tensión a los que es dañino aproximarse. Con todo eso, las líneas que siguen se abrigarán bajo el signo del mejor propósito. $\mathrm{Si}$ alguien quiere tomarlas desde otro ángulo, tanto peor para él.

Al ir a formar juicios sobre sí mismas, las naciones iberoa- 
mericanas pueden verse impulsadas por fuerzas contradictorias: de un lado la creciente e interesada lisonja de los de fuera, y de otro, la desconfianza excesiva respecto del propio país. A menudo se halla en Ibero América al hombre convencional y estirado, sostenido por ortopedias anímicas, y al caído en desaliento, en actitud hipercrítica respecto de su medio. No pensemos ahora en ello sino en las simpatías y esperanzas que cercan a la porción Sur del continente, del cual se aguardan formas de civilización nuevas y salvadoras. Tanto en Ibero América como en el Brasil restenan palabras claras e inteligentes, $y$ apuntan formas de vitalidad colectiva llenas de interés. Gentes de la vieja Europa, hoy angustiada por errores y fatalidades, vuelven su anhelo a esta inmensa porción del planeta, en donde todavía parecen vivas las posibilidades de paz. La coyuntura para Ibero América es única.

A la vez que eso ocurre, los Estados Unidos intensifican su esfuerzo para intimar con la otra América desunida, y ante tal hecho vamos a hacer la primer parada, a fin de notar su sentido y su alcance. Se percibe aquí, en forma más o menos clara, que el gigantesco y maravilloso país no ha logrado en el Sur el éxito que sería legítimo esperar. La expansión política de los últimos cincuenta años y el inflìjo económico hacen que esta mole gravite sobre el Sur, pero no han conseguido imprimir un tono intelectual o espiritual a ninguno de los importantes pueblos de Ibero América, regidos aún por patrones europeos en lo que afecta a las maneras superiores del vivir. Los técnicos, los estudiantes que cada vez en mayor número acuden a las Universidades americanas, serán luego en sus tierras gotas individuales que en poco matizan la organización universitaria, la estructura social, las costumbres politicas, la sanidad pública, etc.

La acción difusa que los Estados Unidos tratan de ejercer sobre la América luso-hispana reviste cada vez aspecto más definido y consciente, y va acompañada por la solicitud oficial. Surgen Institutos, revistas, organizaciones varias, incluso sec- 
ciones en la Secretaría de Estado cuyo tema son las relaciones amistosas y de cultura interamericanas. Universidades importantes se interesan en tal acercamiento bajo el lema de la good neighbor policy - la política del buen vecino. Se percibe, sin duda legítimamente, que la natural expansión del espíritu americano ha de realizarse hacia el Sur, en forma algo similar a como Francia y Alemania actuaron sobre el Sur de Europa en los últimos ochenta años. En ello hay un fondo de buena fe, mucho más de lo que pudiera pensarse desde fuera, pues el americano gusta de ser útil y beneficioso, prescindiendo de que al mismo tiempo pretenda acrecer su exportación, deseo natural que otros países no suelen acompañar de ninguna prestación de servicios. Al yanqui le encantaría contribuir a que Sur América poseyera higiene y sanidad eficientes, bibliotecas $\tan$ perfectas como las de aquí, democracia auténtica, etc. Quisieran además que el profesor norteamericano tuviera en Ibero América el lugar y prestigio de los europeos -españoles, franceses, italianos- que a veces se encuentran allá. La Universidad de San Paulo sería un buen ejemplo para esto.

La causa del diferente tratamiento que aquí notan, es decir, de la preferencia por lo europeo en Ibero América, no proviene únicamente de la superioridad europea, entre otras razones porque ni España ni Italia poseen una ciencia superior a la norteamericana. Lo que ocurre, y el norteamericano no ve o no puede ver, es que aquellos otros países han actuado sobre Ibero América a base de una selección muy. sutil, empleando a veces hombres a mil codos sobre el nivel medio de sus tierras; en cambio los Estados Unidos piensan influir sobre la atención de Ibero América realizando movimientos colectivos, de masas, con lo cual difícilmente se logra lo que se desea. Cuando veo los nobles y laudables esfuerzos de algunos grupos americanos, afanados en atraer la simpatía de sus vecinos, pienso en el error de quien pretendiera clavar un clavo golpeándolo con varias toneladas de cualquier materia valiosa pero fofa -lana por ejemplo. Todo 
ello procede de la idea, en el fondo ingenua, de que Ibero America es algo parecido a los Estados Unidos, y que lo que aquí tiene éxito -el movimiento colectivo en que se sume el individuo- vale para pueblos en que la masa es más indiferente, - y lo único que en verdad cuenta son los individuos, que contradiciéndola, descuellan sobre el montón. Media docena de americanos a lo Waldo Frank, trazarian una huella más profunda que veinte viajes de good will. En el fondo acaba por ser interesante el espectáculo de la incomprensión mutua, basada en las más altas cualidades que se poseen.

En Norte América no hay una Secretaría de Educación, y no existen órganos centrales para analizar o seleccionar las actividades de la cultura. En este caso, la llamada democracia (que es por otra parte la mayor virtud de este pais), ostenta como toda virtud su faz adversa. Una cultura para todos, al nivel de todos, acaba por estrangular al valor selecto, cuya característica fué siempre el enfrentarse con cualquier exigencia gregaria. Sólo como excepción admite el americano que las actividades de la mente, en su estadio esencial, sean perfectamente inútiles y para poquísimos. En sus grados elementales, los más numerosos, la Universidad se parece a los primeros años de un liceo francés, porque en ella se enseña el $a b c$ de todo saber. Sólo en clases muy superiores o en institutos especiales, puede un profesor dar por supuesto que sus oyentes conocen la bibliografía sobre la materia, y exponer novedades complicadas. Entonces aparece el estudiante desinteresado y apto para trabajar en forma interesante.

A pesar de ser considerable el número de norteamericanos intelectualmente muy distinguidos, no hay, por decirlo asi, un escalafón social en que se destaquen las notibilidades de la inteligencia, prescindiendo de que logren o no la popularidad, según hasta hace poco acontecía en Europa, en donde la exquisitez artística o intelectual significaba una última y áurea garantía para la solvencia de cada nación. Son de otra índole los héroes que 
esta América admira y fomenta, lo que a la vez es causa y efecto del sesgo original de tan magnífico pueblo, cuya suprema meta parece ser el logro de la perfección media, en un grado inconmensurable $y$ dentro de la mayor posible libertad.

El acercamiento entre Norte y Sur América, sobre el plano en que hoy parece buscarse, depende en gran parte de que aquí. perciban el alcance, en este caso, de las formas más altas e individualizadas de la cultura, sobre todo en el campo de las llamadas ciencias del espíritu, aptas para captar y aglutinar el interés de la gente suramericana. Las letras, el arte, la historia, e] hablar refinado, el pensar riguroso, tienden a la formación de tipos humanos de alto rango, finalidad que interesa a los pueblos de origen latino más que la creación de masas encuadradas por tina técnica. Realícela en mayor o menor grado, la aspiración para Ibero Ámérica es de carácter aristocrático; por eso el escritor valioso obtiene cargos diplomáticos, dirige bibliotecas, $\mathrm{y}$ con la única credencial de su arte o de su inteligencia, se abre paso a través de la sociedad. Que en casos concretos el dar un cargo profesional a un literato pueda ser un desastre, no invalida lo que digo. A Ibero América sigue interesándole el hombre más que la "cosa", y quienes deseen convivir con esa porción del mundo deben saberlo, entre otros motivos para sacar de ello el beneficio que se deriva de entrar en contacto con toda forma auténtica de civilización. Junto a esto no es menos verdad que el iberoamericano es más dado a oír novedades interesantes que a meditar sostenidamente sobre gruesos y complicados volúmenes. Una conferencia de filosofía, literatura o historia, por apretada y densa que sea, si está hecha con arte, arrastra al público más alto de Río de Janeiro o Buenos Aires como jamás lo harán el técnico o el físico. Por medio de tales conferencias se han ganado el respeto y la simpatía del suramericano los hombres más eminentes de Europa, la cual Europa llevó hasta ahora la gerencia de cuanto en aquellos países significa valías de primer grado. . 
No sé si acertaré a expresar bien lo que pienso, pero mi última idea sobre $\tan$ delicado asunto es que el norteamericano tendría que conceder más aprecio al arte de la expresión, si es que no desea seguir el margen de la mejor Ibero América; y que por su parte el iberoamericano debiera prescindir algún tanto de lo que estime soso y escasamente espectacular, para lograr más provecho de la inmensidad de saberes y técnicas desinteresadas que en este país se cultivan. El iberoamericano, por ejemplo, se interesa escasamente en las llamadas Humanidades, y escaso lo hasta ahora hecho por él con carácter original y universal. En cambio en los Estados Unidos, aun cuando todavía no posean un Mommsen o un Menéndez Pidal, el citar lo producido en este país es inevitable al ir a tratar de tales asuntos. Sobre lingüística y ciencia de la Antiguiedad hay libros y revistas de suma importancia; recuerdo por ejemplo que cuando estaba en la Universidad de Wisconsin, un colega me dijo con la mayor sencillez que acababa de pasar tres años en Grecia recogiendo inscripciones para el monumental Corpus inscriptionum Graecarum que se edita en Alemania. Hay americanos que excavan en Asia y descubren novedades acerca de Babilonia, como puede verse en el Museo Oriental de Chicago. $\mathrm{Y}$ así en multitud de otras ramas de la cultura. Si el norteamericano se preocupara de exponer en forma sistemática la bibliografía de sus trabajos científicos, en manera asequible al resto de América, el resultado sería sorprendente.

Con todas las salvedades. que hayan de establecerse, es evidente que una leve inclinación de los contenidos de la cultura americana bastaria para verter sobre los pueblos del Sur un caudal de posibilidades intelectuales que aquellos tardarian mucho en tutilizar y encauzar. Me temo sin embargo que eso no acontezca en fecha próxima, por falta de deseo de que acontezca, y por ser más fácil gozar de una vida elemental $y$ en nivel bajo, que construir otra en estilo ascendente. El autor de libros rápidos y numerosos es todavía demasiado frecuente en Sur América, si 
bien es cierto que van apareciendo quienes, a esa charla ligera conșigo mismos, prefieren concentrar su mente sobre pocas páginas, apretadas en la expresión y densas de novedades.

Al meditar acerca de lo que pudiera ser el esfuerzo coordinado de ambas Américas para beneficiarse mutuamente en el mejor modo, no puedo silenciar mi temor de que el norteamericano tenga que cambiar bastante las maneras en que actualmente viene procediendo. Para acercarse a Ibero América - ya lo he insinuado- haría falta cierta gracia expresiva y una fuerte selección de los llamados a hacer comprender a Sur América lo que realmente quiere y puede hacer en ella este gran país. De otro modo existe el riesgo de que las mejores iniciativas se pierdan, o no obtengan cuanto de ellas habría que esperar. Ya hemos visto por qué el movimiento en masa es escasamente eficaz respectó de Ibero América, y lo mismo diríamos de las exposiciones valiosas (conferencias, escritos) en estilo ingenuo y al alcance de todos, que evita el matiz dificil y emocional. El americano no puede desmentir su tradición puritana - clave de la enorme fuerza de este pueblo-, pero que acoraza el ánimo contra toda espontaneidad honda y personal. El contacto efectivo con Sur América obligaría al americano a adquirir bienes no menos voluminosos que los que él pueda comunicar con su capacidad activa, si un grupo de gente escogida se colocara en postura crítica respecto de tendencias inveteradas, pero que no son después de todo consubstanciales. Pienso que no es más difícil para un americano el adquirir las cualidades que por lo común le faltan, al ir a expresarse a sí mismo, que para un iberoamericano el trabajar con orden y secuencia en algo que no afecte al pan nuestro de cada día. Para aclarar lo que se dice, tómese la crítica literaria en los Estados Unidos, y se verá cómo elude lo estético y se aferra a lo moral y sociológico, a la erudición, en suma a todo lo que no sea arte y; literatura. Esa mecanización del trabajo histórico viene en gran parte de la imitación dentasiado exclusiva de los procedimientos alemanes del siglo úl- 
timo, a reserva de no haber prestado atención a lo que en el pensar alemán podía haber llevado a otros resultados. Dilthey, Simmel, Vossler, Max Schcler -o Bergson, u Ortega y Gasset- no son inspiradores usuales para la mayoría ocupada en historia literaria. Y huelga decir que los nombres citados pudieran aumentarse hasta la treintena. La especialización, qute creo absurda, de los estudios universitarios, junto con su frecuente elementalidad, priva al estudioso del contacto con la filosofía y con la historia de la civilización, con cuyas attsencias el trabajo literario se reduce a un frio $y$ superficial mecanismo. Las excepciones a lo que digo pondrian mús de relieve su evidencia. La misma lengua inglesa cmpicza a empobrecerse en los medios cultos de $\Lambda$ mérica, porque el universitario, envuelto por el espíritu de masa, no se atreve a eludir el trivialismo elemental. Los libros del siglo pasado se leen realmente poco, y se expone el que habla a no ser entendido a poco que abra el compás de su vocabulario. Esta observación vale igualmente para Ibero América, sobre todo para los países del Río de la Plata que han sufrido la acción de inmigraciones perturbadoras para el idioma, y que carecen de una sólida estructura social que imponga frenos a la chabacancría y a la ignorancia.

Estos son, entre otros, los temas que creo debieran discutirsc en las reuniones y congresos convocados para lograr la mejor inteligencia entre el Norte y el Sur de América. 'Es inútil creer que las dulzuras convencionales vertidas en tales ocasiones pueden eludir o hacer olvidar tan agudos problemas. Es asimismo inútil la ficción diplomática de que ambos mundos americanos pueden intercambiar su cultura en un pie de igualdad, si por cultura se entiende lo que se halla en los libros y acontece en las aulas tuiversitarias. Me parecería preferible, por extraño que parezca, declarar abiertamente que el Sur puede enseñar al Norte arte expresivo, selección individual e inquietud crítica; esto último, desde Sócrates, viene siendo fuente de sabiduria y de éxito para individuos y colectividades: La perfección técnica y el buen 
funcionar de la vida colectiva, por maravillosos que sean, no lo son todo. Me parece, por ejemplo, que la limitación artística del angloamericano para cuanto no es arquitectura y vivir práctico; se corregiria conviviendo espiritualmente con quienes poseen alta tradición y audacia cxpresiva, y saben mañas para proteger las mejores individualidades contra el viento y marea de la ñoñez colectiva. La mejor cabeza argentina, Sarmiento, fué tratado de loco -le llamaban "el loco"-, y aun hay quienes miran de través su memoria. Bolívar y San Martín; por causas diversas, murieron abandonados, a destono con los paises a que habian dado existencia. En general, el iberoamericano, si se salva, ha de conquistarse a sí mismo en pugna con ambientes un tanto terribles, dentro de los cuales suele languidecer (aunque aparentemente triunfando) el conformista - boya inerte sobre el mar de las frases hëchas.

En suma, Norte y Sur en América obtendrán provechos de sus contactos en la medida que sientan plena e inteligentemente sus diferencias, $y$ se sitúen en postura crítica respecto de sí mismos. La ocasión para tales experiencias es única, cuando sobre Europa baten sus alas los cuervos de un mal destino. Ya hoy es visible la fatiga en aquellos paises en donde todavía queda margen para las actividades interesantes; lo que pueda sobrevenir después de la lucha siniestra que amenaza en stu obra viva a los pueblos más esclarecidos de la tierra, Dios lo sabe. Por lo mismo la responsabilidad de este continente occidental es inmensurable, porque ante él se abren encrucijadas hacia todas las inminencias.

Hace años alguien me hizo una inquietante observación: "Las naciones llamadas latinoamericanas no pueden soportar todavía que se les diga la verdad". Mas quien asi hablaba no tenía, como yo, su corazón unido al de la gente luso-hispana. Eso además no es exacto en uma época en que han podido escribirse la Historia de Mérico, por José Vasconcelos, o la Historia de una pasión argentina, por Eduardo Mallea. Hay que decir a Mé3 
xico, en efecto, que en tanto que no sienta de veras que a Hernán Cortés debe el haber salido de la sanguinaria e inerte vida precortesiana, México carecerá del esencial equilibrio que tanto necesita. Las repúblicas hispanas con gran contingente de indios parecen obedecer a una consigna tácita, pues en prosa y verso retóricos reclaman por suya la raza precolombina, o la posterior a su independencia. ¿Vale detenerse ante tamaño error? Cuando se contemplan las ciudades mexicanas, las instituciunes de cultura del pasado, los libros, su originalidad literaria, se queda uno absorto, sin comprender la ceguera de quienes intentan suprimir trescientos años de hispanidad, a reserva de utilizar el contenido de vida superior que hay en ellos. Por fortuna, tal aberración no es general ni faltan en cada país quienes la contradigan; ahí está en primera línea la Argentina, que hace años inició la tarea de su integración histórica, olvidando las ingenuidades del siglo XIX, cuando se escribía que la historia argentina se iniciaba en 1810 , como si no hubieran sido españoles de sut tiempo los que fraguaron la independencia de Hispano-América. $\mathrm{Y}$ cuán honda la videncia (permítaseme una escandalosa digresión que algún día explicaré de San Martín y Rivadivia, que soñaban para sus pueblos con un régimen monárquico, sin que hasta ahora me parezca que haya sido suficientemente valorado lo que hubo tras del anhelo de tan insignes patriotas.

Deseamos para la América luso-hispana una mejor y más enérgica vitalidad, sin espíritu lugareño y fragmentado, ya que la otra fragmentación, la política, es fatalidad irremediable. Que cada una de esas naciones mire por encima de sus fronteras y se muestre insatisfecha, es el mejor voto que puede formularse. Con el mejor propósito, me he limitado a expresar lo que había en mi ánimo al ser gentilmente requerido por el Presidente del Instituto Internacional de Literatura Iberoamericana para que diga qué pienso acerca de la posible relación entre ambas Américas.

Americo Castro, University of Texas. 